\title{
Mucin-1 expression in endometrial tissue of Macaca nemestrina during mid-luteal phase after controlled-ovarian hyperstimulation
}

\author{
NURHUDA SAHAR ${ }^{1}$, PONCO BIROWO ${ }^{2}$, KUSMARDI ${ }^{3}$, DIYAH KRISTIANTY ${ }^{4}$, KARINA RAHMANINGRUM ${ }^{5, \vartheta}$, \\ ADRIANA VIOLA MIRANDA ${ }^{\mathbf{5}}$, AFIF RASYAD ${ }^{\mathbf{5}}$, VIVITRI DEWI PRASASTY ${ }^{6}$ \\ ${ }^{1}$ Department of Biology, Faculty of Medicine, Universitas Indonesia. J1. Salemba Raya No. 4, Jakarta Pusat 10430, Jakarta, Indonesia \\ ${ }^{2}$ Departement Urology, Faculty of Medicine, Universitas Indonesia. Jl. Salemba Raya No. 4, Jakarta Pusat 10430, Jakarta, Indonesia \\ ${ }^{3}$ Department of Anatomical Pathology, Faculty of Medicine, Universitas Indonesia. Jl. Salemba Raya No. 4, Jakarta Pusat 10430, Jakarta, Indonesia \\ ${ }^{4}$ Department of Clinical Pathology, Faculty of Medicine, Universitas Indonesia. Jl. Salemba Raya No. 4, Jakarta Pusat 10430, Jakarta, Indonesia \\ ${ }^{5}$ Faculty of Medicine, Universitas Indonesia. Jl. Salemba Raya No. 4, Jakarta Pusat 10430, Jakarta, Indonesia. Tel./fax.: +62-21-7867222 , "email: \\ karinarahma98@gmail.com. \\ ${ }^{6}$ Faculty of Biotechnology, Universita Katolik Atma Jaya Indonesia. Jl. Jend. Sudirman No. 51, Jakarta Selatan 12930, Jakarta, Indonesia.
}

Manuscript received: 7 January 2021. Revision accepted: 24 March 2021.

\begin{abstract}
Sahar N, Birowo P, Kusmardi, Kristianty D, Rahmaningrum K, Miranda AV, Rasyad A, Prasasty VD. 2021. Mucin-1 expression in endometrial tissue of Macaca nemestrina during mid-luteal phase after controlled-ovarian hyperstimulation. Biodiversitas 22: 1927-1933. Endometrial receptivity is one of the factors for successful implantation in pregnancy. Controlled ovarian hyperstimulation $(\mathrm{COH})$ is a required step of in vitro fertilization (IVF), one of the standard procedures to overcome infertility. Exogenous gonadotropin hormones from $\mathrm{COH}$ provoke the secretion of estrogen and progesterone from the ovaries in higher amounts. The supraphysiological environment could impact the endometrial receptivity of the implantation process. Mucin-1 (MUC1) can be used as a marker to indicate alterations in the endometrial tissue. Therefore, this study aimed to investigate the alteration of mucin-1 expression in endometrial tissue of Macaca nemestrina after $\mathrm{COH}$ protocol. This study used endometrium tissue of M. nemestrina embedded with paraffin as tissue blocks. The subjects were 15 female macaques in reproductive age (8-10 years old) with a history of producing offspring. These macaques were classified into four groups based on the $\mathrm{COH}$ protocols, which consist of administering gonadotropin-releasing hormone $(\mathrm{GnRH})$ agonist and recombinant FSH (r-FSH) with dosages of 30 IU, 50 IU, 70 IU (intervention groups), and no r-FSH (control group). The stimulations were administered for 14 days during the mid-luteal phase. Moreover, tissue staining was done by using immunohistochemistry. Mucin-1 expression was analyzed manually for glandular and luminal compartments and automatically for the stromal compartment by Red Green Blue (RGB) measure plugin as a color image from ImageJ software. The expression of mucin-1 was counted semi-quantitatively as H-score. Mucin-1 expression differences in endometrial tissue were assessed by one-way ANOVA with a significant difference found in the glandular part and insignificant results found in luminal and stromal parts. Pearson correlation test was also performed to determine the relationship of steroidal hormones and mucin-1 expression in glandular and luminal compartments. Both correlations were statistically insignificant. However, a positive correlation was found with the glandular compartment and a negative correlation with luminal compartment. As the subject species, M. nemestrina is limited for research utilization in our country, small number of subjects becomes a limitation of this study. Further studies need to be conducted to deepen the understanding of the regulation of mucin-1 expression, particularly by the altered concentrations of steroidal hormones as a consequence of $\mathrm{COH}$.
\end{abstract}

Keywords: Mucin-1, controlled ovarian hyperstimulation, in vitro fertilization, endometrial receptivity

\section{INTRODUCTION}

In vitro fertilization (IVF) is one of the standard procedures to overcome prolonged infertility. In 2012, the number of newborns from IVF had reached five million as IVF has been carried out annually around 1.5 million times (cycles) worldwide. This number is expected to continue rising (Gallos et al. 2017). However, several factors influence the success of IVF. These include the patient age, the etiology of infertility, the duration of infertility, the quality of oocytes, the quality of transferred embryos, and endometrial receptivity (Bhattacharya et al. 2013; Sarais et al. 2016; Ozgu-Erdinc et al. 2020). The number and quality of oocytes and endometrial receptivity are strongly influenced by controlled ovarian hyperstimulation $(\mathrm{COH})$ due to the supraphysiological effect it exerts (Sakiner et al. 2018; Geng et al. 2019).

$\mathrm{COH}$ is one of the required steps in IVF that aims to produce a sufficient number of oocytes to minimize limitations and errors in the laboratory. The protocol is done by administering exogenous gonadotropin (Baskind et al. 2014). This causes the ovaries to produce steroid hormones such as estrogen and progesterone (Gallos et al. 2017). One of the affected tissues is the uterine endometrial tissue because the endometrium is a dynamic tissue whose changes are influenced by ovarian steroid hormones (Sakiner et al. 2018). As a result, $\mathrm{COH}$ will affect the period of endometrial receptivity. On the other side, implantation is an event heavily dependent on endometrial receptivity (day 19-21), which is known as the implantation 
window. The asynchronous event causes the IVF procedure to fail (Shapiro et al. 2011).

The ability to identify the implantation window in a clinical setting can increase the effectiveness of IVF. Several molecules are biomarkers of endometrial receptivity, including mucin-1 (Mahajan 2015; Wu et al. 2018). Mucin-1 is expressed as a glycoprotein in the endometrium that acts as an anti-adhesion for the embryo. It prevents implantation at inappropriate times and areas of the endometrium (Wu et al. 2018). The steroidal hormones, namely progesterone and estradiol, were upregulatedmucin-1 expression during the endometrium receptive phase. When the adhesion phase occurs, a human blastocyst causes degradation of this anti-adhesive molecule at the implantation site, thus causing implantation (Ojosnegros et al. 2021). However, determining a receptive endometrium by taking endometrial tissue from humans is not in line with the rules of research bioethics. Therefore, this study was carried out in the endometrial tissue of $M$. nemestrina in the mid-luteal phase as a breakthrough since it has never been done before. The study aimed to assess the expression of mucin- 1 in the endometrial tissue as a result of $\mathrm{COH}$.

\section{MATERIALS AND METHODS}

\section{Animal model}

This study used paraffin-embedded tissue blocks of the Macaca nemestrina uterus. Subjects incorporated in this study were 15 female macaques in their reproductive age (8-10 years old) weighing about $10-15 \mathrm{~kg}$ with a history of producing offspring. These macaques were divided into four groups corresponding to their $\mathrm{COH}$ protocols, particularly the administration of Gonadotropin-releasing hormone $(\mathrm{GnRH})$ agonist and recombinant-folliclestimulating hormone (r-FSH) with dosages of $30 \mathrm{IU}, 50 \mathrm{IU}$, 70 IU, and no r-FSH (Sahar et al. 2019). The first three groups are the intervention groups and the latter group is the control group. GnRH agonist was given for 14 days. Meanwhile, r-FSH was given for 10-12 days, and both administrations were given throughout the mid-luteal phase. Ovulation stimulation was conducted through HCG administration, which was only authorized if the $\mathrm{COH}$ protocol successfully stabilized the macaques menstrual and ovarian cycles. On days 20 to 22 of the mid-luteal phase, endometrial tissues were retrieved and embedded into paraffin blocks. The Research Ethics Committee approved all the experimental protocols with macaque models of Faculty of Medicine Universitas Indonesia (1441/UN2.F1/ETIK/XII/2018).

\section{Immunohistochemistry assay}

Endometrial tissues were retrieved from paraffin blocks stained with immunohistochemistry assay (Sahar et al. 2019). Firstly, endometrial tissues of Macaca nemestrina embedded in paraffin blocks were cut with a thickness of $3.5 \mu \mathrm{m}$. Antigen retrieval was conducted in Tris EDTA- contained container $(\mathrm{pH}=9)$ heated in Retrieval Generation One BioGear at $98^{\circ} \mathrm{C}$ for 15 minutes. Incubation of mucin-1 monoclonal antibody was done for 24 hours (overnight) at $4^{\circ} \mathrm{C}$.

\section{Image acquisition}

Each tissue was measured by the immunoreactivity of three endometrial components: glandular, luminal, and stromal compartments. Images were acquired by using a camera and IndoMicroView software. Images were taken from a microscope with 400x optical magnification.

\section{Data extraction}

Images of endometrial components were exported from IndoMicroView software as TIF-type images. Immunoreactivity to mucin-1 was divided into four categories according to the number of positive cells: negative, low positive, positive, and high positive. The percentage of each cell group was quantified by an assessment based on the researcher consensus. This assessment was done manually for glandular and luminal compartments. Such an assessment was done independently to avoid bias. Meanwhile, the color intensity of stromal compartments was determined by using a "RGB Measure" plugin from ImageJ software. The assessment for the stromal part included the vascular components that are scattered within the tissue. The percentages of the color intensity were used to score the histological score (H-score) for each object-glass. The histological score formula is given below ( $p i$ is the percentage of cells with $i$ stain, where $i$ is immunoreactivity).

$$
\text { Histological score }=\sum \text { pix } i
$$

\section{Statistical analysis}

Statistical analysis was conducted using SPSS release 24. Normality tests and homogeneity tests were conducted to find correlations between the four designated groups histological scores (one control and three intervention groups). Post hoc analysis was done by using Tukey HSD (Honestly Significant Difference) test. Bivariate correlation analysis was also performed by using the Pearson test.

\section{RESULTS AND DISCUSSION}

The results of mucin-1 expression in glandular, luminal, and stromal compartments of the endometrium

The results from glandular, luminal, and stromal compartments of endometrium showed positive expression for mucin-1 as depicted in Figure 1.A-E. Figure 1.A-C are from the intervention groups. Figure 1.D shows the negative control of endometrial tissue as it was not given mucin-1 antibody, thus did not show positive expression of mucin-1. Figure 1e shows a positive expression of mucin-1 from the glandular compartment without $\mathrm{COH}$ protocol. 


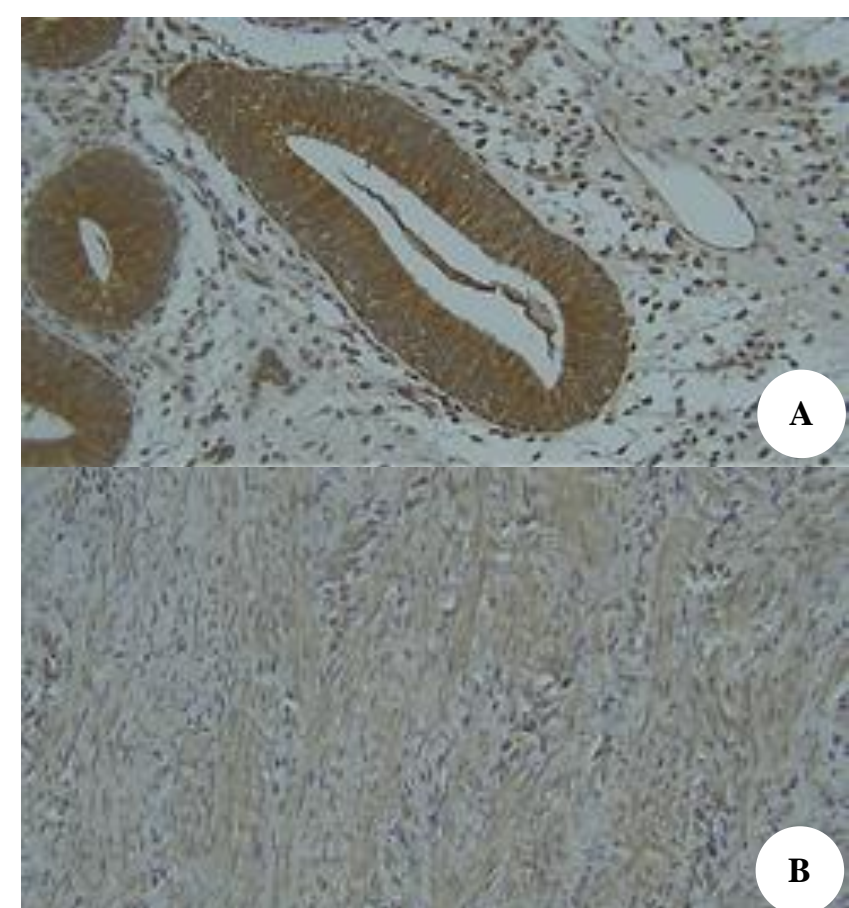

B

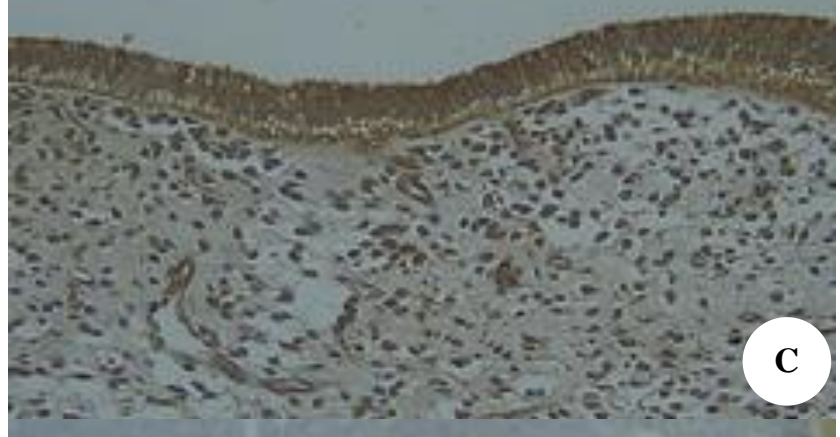

C

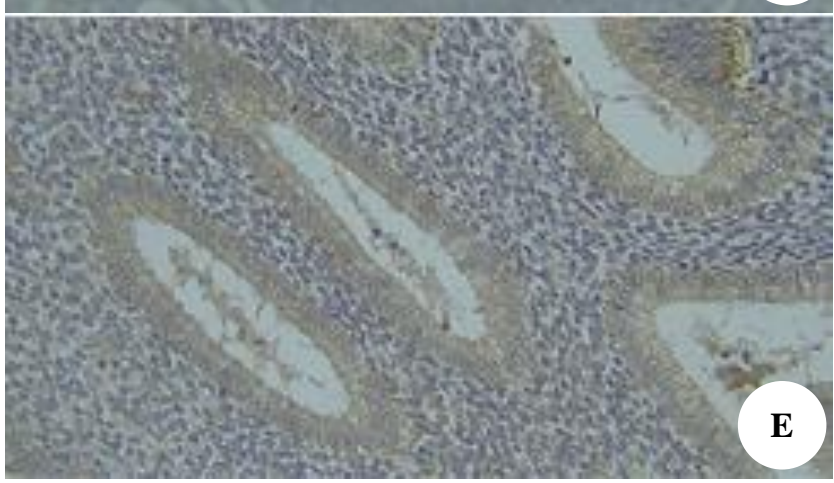

Figure 1. Immunohistopathology morphology: A. Immunostaining result of the endometrial gland; B. Immunostaining result of endometrial stroma; C. Immunostaining result of the endometrial lumen; D. Negative control of endometrial tissue (glandular compartment); E. Positive control of endometrial tissue (glandular compartment). The optical magnification was 400x

After r-FSH was administered, mucin-1 expression employing $\mathrm{H}$-score was analyzed. The results showed that the highest expression was found in the endometrium luminal and glandular compartments, as shown in Figure 2. Meanwhile, the stromal compartment of the endometrium showed a lower expression of mucin-1. This was due to the origin of glandular and luminal compartments originating from epithelial cell lines that produced and secreted mucin1 in a higher amount than that of the stromal compartment of the endometrium originating from mesenchymal cell lines (Crha et al. 2019; Owusu-Akyaw et al. 2019). The intervention group with a dosage of $30 \mathrm{IU}$ from the luminal compartment was not shown due to the damaged samples. Figure 2 shows that a higher dosage of r-FSH caused a lowered expression of mucin-1. However, such a pattern was not found in the glandular compartment. H-score of mucin-1 in the glandular compartment went significantly higher after r-FSH administration with a dosage of 30 IU and reached the highest expression with a dosage of 50 IU. In contrast, the expression went lower in the intervention group with a dosage of 70 IU. Regardless of that, the intervention group with a dosage of 70 IU still had a higher expression compared to the control group.

The difference of mucin-1 expression within endometrial glands among intervention groups was significant as determined by one-way ANOVA $(\mathrm{F}$ (3.10) $=$ 7.474, $p=0.007)$. Insignificant results were shown in luminal $(\mathrm{F}(3.8)=1.129, p=0.394)$ and stromal $(\mathrm{F}(3.11)=$ $1.195, p=0.357)$ parts of the endometrial tissues. The stromal compartment showing insignificant result may be explained by the low expression of mucin-1 per definition (Horne et al. 2002). In contrast, the insignificant result from the luminal compartment may be explained by the limited localization of the mucin-1 expression in luminal cells during the receptive phase as it is controlled by progesterone (Wu et al. 2019).

Post hoc analysis using the Tukey HSD test was conducted to determine which groups of the glandular component may have significant differences. The results showed a significant difference between the control group and the intervention groups with dosages of 30 IU ( $p=$ $0.021)$ and $50 \mathrm{IU}(p=0.007)$. There was no significant difference between the control group and the intervention group with a dosage of $70 \mathrm{IU}(p=0.316)$. There were no significant differences either between the intervention groups with dosages of $30 \mathrm{IU}$ and $50 \mathrm{IU}(p=0.977), 30 \mathrm{IU}$ and $70 \mathrm{IU}(p=0.394)$, or $50 \mathrm{IU}$ and $70 \mathrm{IU}(p=0.197)$. These insignificant differences among the intervention groups demonstrate that there was no dose-response relationship. The result of the Tukey HSD test is shown in Table 4. 


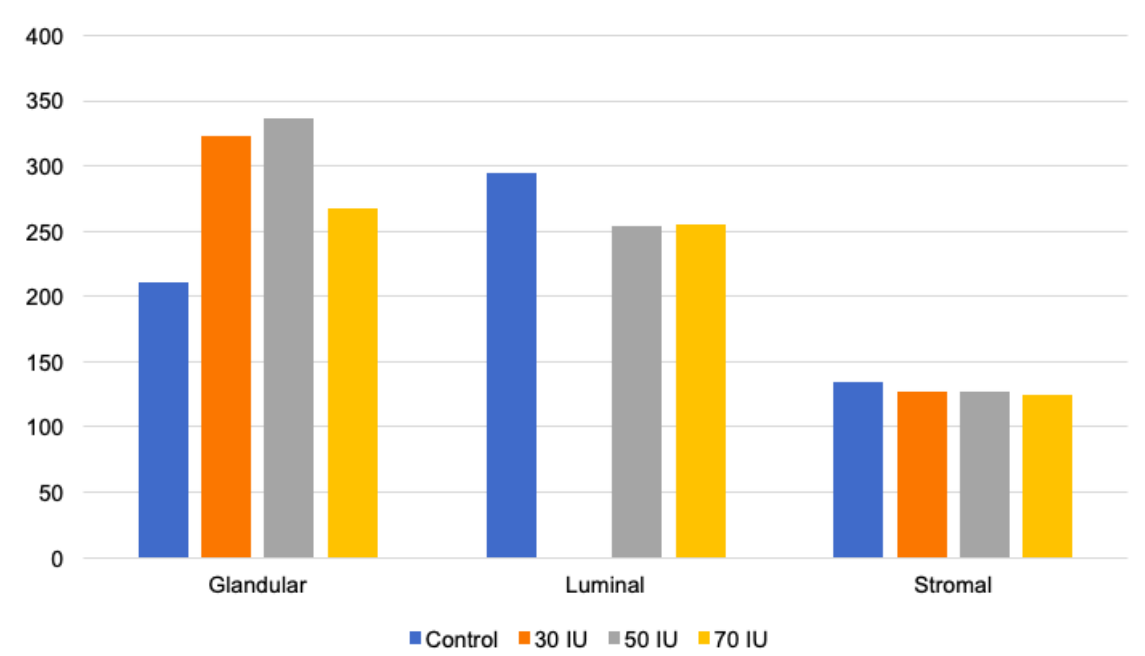

Figure 2. H-score of each endometrial compartment of Macaca nemestrina with the corresponding r-FSH doses and control group. 30 IU of the luminal endometrial sample was damaged

Table 1. Statistical result for the glandular compartment of endometrial tissue using ANOVA

\begin{tabular}{lccccc}
\hline & Sum of squares & df & Mean square & F & p-value \\
\hline Between Groups & 37718.049 & 3 & 12572.683 & 7.474 & 0.007 \\
Within Groups & 16822.850 & 10 & 1682.285 & & \\
Total & 54540.899 & 13 & & & \\
\hline
\end{tabular}

Table 2. Statistical result for the luminal compartment of endometrial tissue using ANOVA

\begin{tabular}{lccccc}
\hline & Sum of squares & df & Mean square & F & $p$-value \\
\hline Between Groups & 6617.171 & 3 & 2205.724 & 1.129 & 0.394 \\
Within Groups & 15626.588 & 8 & 1953.199 & & \\
Total & 22242.759 & 11 & & & \\
\hline
\end{tabular}

Table 3. Statistical result for the stromal compartment of endometrial tissue using ANOVA

\begin{tabular}{lccccc}
\hline & Sum of squares & df & Mean square & F & $p$-value \\
\hline Between Groups & 184.892 & 3 & 61.631 & 1.195 & 0.357 \\
Within Groups & 567.148 & 11 & 51.559 & & \\
Total & 752.040 & 14 & & \\
\hline
\end{tabular}

Table 4. Tukey HSD result for the glandular compartment of endometrium

\begin{tabular}{|c|c|c|c|c|c|c|}
\hline \multirow{2}{*}{ Group (I) } & \multirow{2}{*}{ Group $(\mathbf{J})$} & \multirow{2}{*}{$\begin{array}{c}\text { Mean difference } \\
\text { (I-J) }\end{array}$} & \multirow{2}{*}{$\begin{array}{l}\text { Standard } \\
\text { Error }\end{array}$} & \multirow{2}{*}{$p$-value } & \multicolumn{2}{|c|}{$\mathbf{9 5 \%}$ confidence interval } \\
\hline & & & & & Lower bound & Upper bound \\
\hline \multirow{3}{*}{ Control } & $30 \mathrm{IU}$ & $-112.73083^{*}$ & 31.32623 & 0.021 & -208.5689 & -16.8927 \\
\hline & $50 \mathrm{IU}$ & $-125.28250^{*}$ & 29.00246 & 0.007 & -214.0113 & -36.5537 \\
\hline & $70 \mathrm{IU}$ & -57.28417 & 31.32623 & 0.316 & -153.1223 & 38.5539 \\
\hline \multirow{3}{*}{$30 \mathrm{IU}$} & Control & $112.73083^{*}$ & 31.32623 & 0.021 & 16.8927 & 208.5689 \\
\hline & $50 \mathrm{IU}$ & -12.55167 & 31.32623 & 0.977 & -108.3898 & 83.2864 \\
\hline & $70 \mathrm{IU}$ & 55.44667 & 33.48915 & 0.394 & -47.0086 & 157.9019 \\
\hline \multirow{3}{*}{$50 \mathrm{IU}$} & Control & $125.28250^{*}$ & 29.00246 & 0.007 & 36.5537 & 214.0113 \\
\hline & $30 \mathrm{IU}$ & 12.55167 & 31.32623 & 0.977 & -83.2864 & 108.3898 \\
\hline & $70 \mathrm{IU}$ & 67.99833 & 31.32623 & 0.197 & -27.8398 & 163.8364 \\
\hline \multirow{3}{*}{$70 \mathrm{IU}$} & Control & 57.28417 & 31.32623 & 0.316 & -38.5539 & 153.1223 \\
\hline & $30 \mathrm{IU}$ & -55.44667 & 33.48915 & 0.394 & -157.9019 & 47.0086 \\
\hline & $50 \mathrm{IU}$ & -67.99833 & 31.32623 & 0.197 & -163.8364 & 27.8398 \\
\hline
\end{tabular}


Regarding the effects of $\mathrm{COH}$ on mucin-1 expression, $\mathrm{Wu}$ et al. (2019) performed a study to determine mucin-1 expression on mice endometrial tissue and it showed insignificant results to the glandular and luminal compartments in the peri-implantation phase. The study also showed lowered mucin-1 expression in both compartments. These results are similar to this study results in which $\mathrm{COH}$ influence on the luminal compartment was insignificant and decreased the mucin-1 expression. However, the result differs from this study in which mucin1 expression increased in the glandular compartment. Xu et al. (2012) also performed a study to assess mucin-1 expression in human endometrial tissue using Real-Time PCR and immunohistochemistry assay. The results showed reduced mucin-1 expression in both glandular and luminal compartments, while this study only showed reduced mucin-1 expression in the luminal compartment, not in the glandular compartment. Such a dose given to human subjects was equivalent to this study in which r-FSH dosage of $50 \mathrm{IU}$ was given to Macaca nemestrina subjects. The administration of r-FSH explains that the dose adjusts the sample weight. As previously stated, both studies showed a lowered endometrial receptivity as explained by the lowered mucin-1 expression on the luminal compartment as well as the glandular compartment. On the contrary, the glandular compartment result in this study showed increased mucin-1 expression after $\mathrm{COH}$. Such a result may be explained by several factors such as sample and protocol differences.

\section{The relationship of steroidal hormones and mucin-1 expression in luminal and glandular compartments of endometrium}

To identify the relationship between steroidal hormones (progesterone and estradiol) and mucin-1 expression, the H-score was assessed from glandular and luminal compartments considering a higher expression of mucin-1 compared to the stromal compartment (Crha et al. 2019; Owusu-Akyaw et al. 2019).

Table 5 shows various steroidal hormone concentrations (progesterone and estradiol), and the $\mathrm{H}$ score of mucin- 1 after the samples in intervention groups were administered with r-FSH with dosages of 30 IU, 50 IU, and $70 \mathrm{IU}$. These results show that each group and the control group showed a different response of mucin-1 expression due to altered hormonal concentrations.

A Pearson bivariate correlation test was also performed to determine the relationship between the steroidal hormone concentrations (progesterone and estradiol) and mucin-1 expression employing $\mathrm{H}$-score. The results vary from the luminal and glandular compartments. Table 6 shows the result of the Pearson test for progesterone and glandular H-score. There was a positive correlation between progesterone and glandular $\mathrm{H}$-score, which was statistically insignificant $(\mathrm{r}=0.129, \mathrm{n}=14, p=0.659)$. Similar result was found for estradiol and glandular $\mathrm{H}-$ score as shown in Table $7(\mathrm{r}=0.148, \mathrm{n}=14, p=0.613)$. Meanwhile, a statistically insignificant negative correlation was found in the result for progesterone and luminal $\mathrm{H}$ - score as shown in Table $8(\mathrm{r}=-0.06, \mathrm{n}=12, p=0.854)$. Similar result was found as well for estradiol and luminal $\mathrm{H}$-score as shown in Table $9(\mathrm{r}=-0.121, \mathrm{n}=12, p=0.708)$. Scatter box plots are also shown in Figure 7 for steroidal hormones and the $\mathrm{H}$-score of glandular and luminal compartments.

The positive correlation of steroidal hormones in the glandular compartment explains that higher steroidal hormones will increase the expression of mucin-1, although statistically insignificant. This finding is in line with the theory in which the physiological influence of steroidal hormones, namely progesterone and estradiol, will increase mucin-1 expression in humans (Bhurke et al. 2016; Jing et al. 2019). On the contrary, the luminal compartment showed a negative correlation, which implies the negative relationship between steroidal hormones and the luminal compartment of $M$. nemestrina endometrium. Such a result may be explained by the downregulation mechanism by progesterone through the progesterone receptor (PR) indirectly, in which PR will interact with the estrogen receptor (ER) (Gebru 2006). In addition to that, PR has two isoforms, PRA and PRB, which regulate the mucin-1 gene (MUC1) expression differently. Activated PRB will stimulate the activity of the MUC1 promoter, whereas PRA will suppress MUC1 gene activity on the human epithelial uterus cell line. Other factors, such as biological coregulators, which include coactivators and corepressors, influence the work of progesterone receptors. As previously stated, different determinants could influence the activity of MUC1 gene, which may elucidate the lowered expression of mucin-1 in the luminal compartment. However, in this study, the difference of PR isoforms in samples was not assessed.

Another explanation is the different regulation of mucin-1 expression that takes place in the luminal and glandular compartment. This is consistent with a study conducted on human uterus by Shen et al. (2015). After the sample was exposed to higher progesterone and estrogen, there was a reduction in the mucin-1 expression in the luminal compartment. The lowered progesterone receptors explained this finding from the cells. Progesterone regulation was proven by giving antiprogestin, which prevents the downregulation of both PR and mucin-1. The luminal compartment with higher steroidal hormones, as a result of $\mathrm{COH}$, would decrease the expression of mucin-1. The study performed on Papio anubis showed the persistent expression of mucin-1 in basal endometrium, likewise for PR. It may explain the result of this study in which the glandular compartment of $M$. nemestrina uterus had a positive correlation between steroidal hormones and mucin-1 expression (Zheng 2008).

One of the limitations of this study is the small number of subjects since $M$. nemestrina is restricted for research utilization. Variation of follicular reserves between samples was also not measured. This is due to the fact that variations in follicular reserves can cause variations in the concentration of steroidal hormones, which are the stimulators of the expression of mucin-1 in the endometrium. 
Table 5. Steroidal hormone concentrations and H-score of glandular and luminal compartments

\begin{tabular}{lcccc}
\hline \multicolumn{1}{c}{ Group } & Glandular H-score & Luminal H-score & Progesterone $(\mathbf{n g} / \mathbf{m L})$ & Estradiol $(\mathbf{p g} / \mathbf{m L})$ \\
\hline Control & 210.71 & 294.77 & 0.31 & 548.25 \\
30 IU & 323.44 & damaged sample & 1.62 & 731.33 \\
50 IU & 335.99 & 253.42 & 7.91 & 1290.5 \\
70 IU & 267.99 & 255.79 & 2.48 & 1334.67 \\
\hline
\end{tabular}

Table 6. Pearson correlation for progesterone and glandular $\mathrm{H}-$ score

\begin{tabular}{|c|c|c|c|c|c|c|c|}
\hline & & Progesterone & $\begin{array}{c}\text { Glandular } \\
\text { H-score }\end{array}$ & & & Progesterone & $\begin{array}{c}\text { Glandular } \\
\text { H-score }\end{array}$ \\
\hline \multirow[t]{3}{*}{ Progesterone } & Pearson Correlation & 1 & 0.129 & \multirow[t]{3}{*}{ Progesterone } & Pearson Correlation & 1 & -0.060 \\
\hline & Sig. (2-tailed) & & 0.659 & & Sig. (2-tailed) & & 0.854 \\
\hline & $\mathrm{N}$ & 15 & 14 & & $\mathrm{~N}$ & 15 & 12 \\
\hline Glandular & Pearson Correlation & 0.129 & 1 & Luminal & Pearson Correlation & -0.060 & 1 \\
\hline \multirow[t]{2}{*}{ H-score } & Sig. (2-tailed) & 0.659 & & \multirow[t]{2}{*}{ H-score } & Sig. (2-tailed) & 0.854 & \\
\hline & $\mathrm{N}$ & 14 & 14 & & $\mathrm{~N}$ & 12 & 12 \\
\hline
\end{tabular}

Table 7. Pearson correlation for estradiol and glandular H-score

Table 9. Pearson correlation for estradiol and luminal H-score

\begin{tabular}{|c|c|c|c|c|c|c|c|}
\hline & & Progesterone & $\begin{array}{c}\text { Glandular } \\
\text { H-score }\end{array}$ & & & Progesterone & $\begin{array}{c}\text { Glandular } \\
\text { H-score }\end{array}$ \\
\hline \multirow{3}{*}{ Estradiol } & Pearson Correlation & 1 & 0.148 & Estradiol & Pearson Correlation & 1 & -0.121 \\
\hline & Sig. (2-tailed) & & 0.613 & & Sig. (2-tailed) & & 0.708 \\
\hline & $\mathrm{N}$ & 15 & 14 & & $\mathrm{~N}$ & 15 & 12 \\
\hline Glandular & Pearson Correlation & 0.148 & 1 & Luminal & Pearson Correlation & -0.121 & 1 \\
\hline \multirow{2}{*}{ H-score } & Sig. (2-tailed) & 0.613 & & H-score & Sig. (2-tailed) & 0.708 & \\
\hline & $\mathrm{N}$ & 14 & 14 & & $\mathrm{~N}$ & 12 & 12 \\
\hline
\end{tabular}
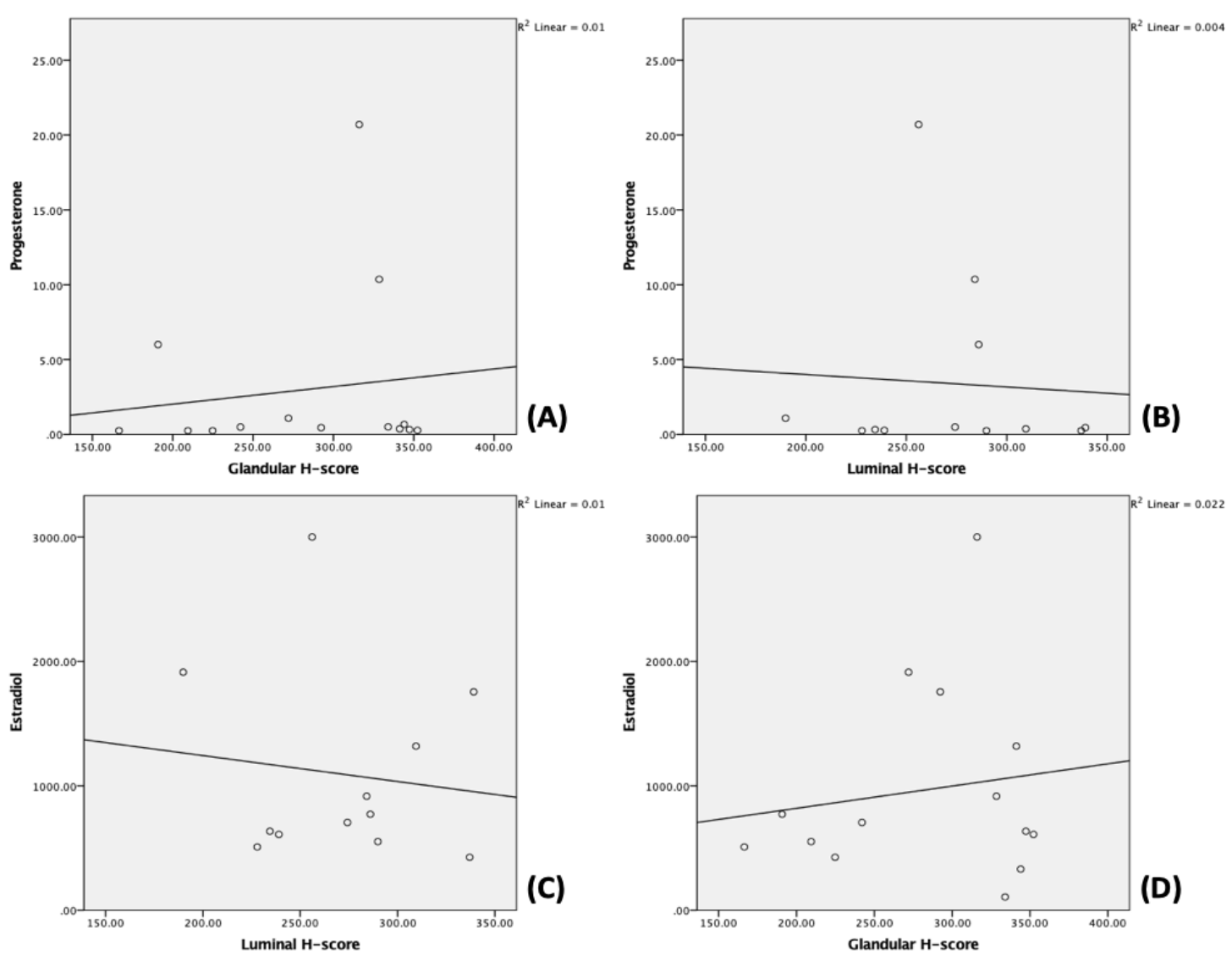

Figure 3. Scatter-plot graphs for progesterone and glandular H-score (A), progesterone and luminal H-score (B), estradiol and glandular $\mathrm{H}$-score (C), and estradiol and luminal H-score (D) 
In conclusion, controlled ovarian hyperstimulation affects mucin-1 expression in endometrial glands significantly but not in the luminal and stromal parts of the endometrial tissue of $M$. nemestrina. The relationship between the steroidal hormones (progesterone and estradiol) and mucin-1 expression utilizing $\mathrm{H}$-score showed insignificant results. The different mucin-1 expression found in the luminal and glandular compartments may be due to the different regulation in both compartments of endometrial tissue of $M$. nemestrina. Further studies need to be conducted to deepen the understanding of the regulation of mucin-1 expression, particularly by the altered concentrations of steroidal hormones as a consequence of $\mathrm{COH}$.

\section{ACKNOWLEDGEMENTS}

We would like to thank the Director of Research and Public Services, Universitas Indonesia for supporting the PITA and PDUPT research grants.

\section{REFERENCES}

Baskind NE, Orsi NM, Sharma V. 2014. Impact of exogenous gonadotropin stimulation on circulatory and follicular fluid cytokine profiles. Intl J Reprod Biomed 2014: e218769. DOI: $10.1155 / 2014 / 218769$.

Bhattacharya S, Maheshwari A, Mollison J. 2013. Factors associated with failed treatment: An analysis of 121,744 women embarking on their first IVF cycles. PLoS ONE 8: e0082249. DOI: 10.1371/journal.pone.0082249.

Bhurke AS, Bagchi IC, Bagchi MK. 2016. Progesterone-regulated endometrial factors controlling implantation. Am J Reprod Immunol 75 (3): 237-245. DOI: 10.1111/aji.12473.

Crha K, Ventruba P, Zakova J, Jeseta M, Pilka R, Vodicka J, Serpa P. 2019. The role of mesenchymal-epithelial transition in endometrial function and receptivity. Ceska Gynekol 84 (5): 371-375.

Gallos ID, Eapen A, Price MJ, Sunkara SK, Macklon NS, Bhattacharya S, Khalaf Y, Tobias A, Deeks JJ, Rajkhowa M. 2017. Controlled ovarian stimulation protocols for assisted reproduction: A network meta-analysis. Cochrane Database Syst Rev 2017: 1-25. DOI: 10.1002/14651858.CD012586.

Gebru ST. 2006. Uterotrophic and Antiuterotrophic Actions of Estrogen and Tamoxifen: Analysis of Expression and/or Suppression of Estrogen Dependent Genes in the Rat Uterine Systems. [Dissertation]. Howard University, Washington DC., USA.

Geng Y, Xun Y, Hu S, Lai Q, Jin L. 2019. GnRH antagonist versus follicular-phase single-dose GnRH agonist protocol in patients of normal ovarian responses during controlled ovarian stimulation.
Gynecol Endocrinol 35 (4): 309-313. DOI: 10.1080/09513590.2018.1528221.

Jing X, Liang H, Hao C, Yang X, Cui X. 2019. Overexpression of MUC1 predicts poor prognosis in patients with breast cancer. Oncol Rep 41 (2): 801-810. DOI: 10.3892/or.2018.6887.

Mahajan N. 2015. Endometrial receptivity array: Clinical application. J Hum Reprod Sci 8: 121-129. DOI: 10.4103/0974-1208.165153.

Ojosnegros S, Seriola A, Godeau AL, Veiga A. 2021. Embryo implantation in the laboratory: An update on current techniques. Hum Reprod Update. DOI: 10.1093/humupd/dmaa054.

Owusu-Akyaw A, Krishnamoorthy K, Goldsmith LT, Morelli SS. 2019. The role of mesenchymal-epithelial transition in endometrial function. Hum Reprod Update 25(1): 114-133. DOI: 10.1093/humupd/dmy035.

Ozgu-Erdinc AS, Coskun B, Yorganci A, Hancerliogullari N, Yilmaz N, Engin-Ustun Y. 2020. The role of inflammatory hematological markers in predicting IVF success. JBRA Assist Reprod. DOI: 10.5935/1518-0557.20200050.

Sahar N, Mujihartini N, Pudjianto DA, Pradhita AD, Thuffi R, Kusmardi K. 2019. Increased progesterone on the day of administration of hcg in controlled ovarian hyperstimulation affects the expression of HOXA10 in primates' endometrial receptivity. Biomedicines 7: 1-8. DOI: 10.3390/biomedicines7040083.

Sakiner L, Bulut ID, Yalcinkaya P, Elmas C. 2018. Effects of controlled ovarian hyperstimulation protocols on uterine markers. J Turgut Ozal Med Cent 25: 1-4. DOI: 10.5455/annalsmedres.2018.04.064.

Sarais V, Reschini M, Busnelli A, Biancardi R, Paffoni A, Somigliana E. 2016. Predicting the success of IVF: external validation of the van Loendersloot's model. Hum Reprod 31(6): 1245-1252. DOI: 10.1093/humrep/dew069.

Shapiro BS, Daneshmand ST, Garner FC, Aguirre M, Hudson C, Thomas S. 2011. Evidence of impaired endometrial receptivity after ovarian stimulation for in vitro fertilization: A prospective randomized trial comparing fresh and frozen-thawed embryo transfer in normal responders. Fertil Steril 96: 344-348. DOI: 10.1016/j.fertnstert.2011.05.050.

Shen F, Yan C, Liu M, Feng Y, Chen Y. 2015. Decreased expression of mucin-1 in endometriosis endometrium correlated with progesterone receptor B involved in infertility. Arch Gynecol Obstet 291(2): 439445. DOI: 10.1007/s00404-014-3419-x.

Wu F, Chen X, Liu Y, Liang B, Xu H, Li TC, Wang CC. 2018. Decreased MUC1 in endometrium is an independent receptivity marker in recurrent implantation failure during implantation window. Reprod Biol Endocrinol 16 (1): 60. DOI: 10.1186/s12958-018-0379-1.

Wu F, Mao D, Liu Y, Chen X, Xu H, Li TC, Wang CC. 2019. Localization of Mucin 1 in endometrial luminal epithelium and its expression in women with reproductive failure during implantation window. J Mol Histol 50: 563-572. DOI: 10.1007/s10735-019-098486.

Xu B, Sun X, Li L, Wu L, Zhang A, Feng Y. 2012. Pinopodes, leukemia inhibitory factor, integrin-beta3, and mucin-1 expression in the periimplantation endometrium of women with unexplained recurrent pregnancy loss. Fertil Steril 98 (2): 389-395. DOI: 10.1016/j.fertnstert.2012.04.032.

Zheng Y. 2008. In Situ and in Vitro Immunolocalization of Oviductin Binding Sites on Hamster Uterine Epithelial Cells and Detection of a Hamster Oviductin Homologue in the Female Rat Reproductive Tract. [Thesis]. Queen's University, Ontario, Canada. 